\title{
Identification of Adverse Drug Reactions in Congestive Heart Failure Patients in a Tertiary Care Hospital, West Nusa Tenggara, Indonesia
}

\author{
Dita Marina Lupitaningrum*, Putri Ramdaniah, Depi Yuliana \\ University of Qamarul Huda Badaruddin, Central Lombok, West Nusa Tenggara, Indonesia
}

\begin{abstract}
Congestive Heart Failure (CHF) is a progressive health problem with high mortality and morbidity and has the potential to develop adverse drug reactions (ADRs). This study was conducted to determine the prevalence of potential ADRs, the types of drugs that cause ADRs, the types of ADRs, and the risk factors that affect the ADRs in CHF patients. Data were collected using medical record of hospitalized patient at the West Nusa Tenggara (NTB) Provincial Hospital, Indonesia, in 2017 to 2019. The assessment of the causality and severity of ADRs used the Naranjo algorithm and the Hartwig and Siegel scale. This study used 325 CHF patients' data. Of 325 CHF patients, 223 patients $(69 \%)$ were recorded as having ADRs with 446 total cases of ADRs, consisted of $4(0.9 \%)$ highly probable, 187 (41.9\%) probable, and $255(57.2 \%)$ possible. The drugs that cause ADRs with a highly probable status are bisoprolol and ramipril. The most ADRs categories were level $1(76.0 \%)$, followed by level $2(17.3 \%)$, level $3(6.5 \%)$, and level $4 \mathrm{~A}(0.2 \%)$. The most affected organ systems were the muscles, joints, and nervous system $(\mathrm{n}=136,37.7 \%)$, followed by renal, and gastrointestinal system. No association between ADRs with several risk factors, such as gender, age, and comorbidities. The prevalence of ADRs in CHF patients in this study was $69 \%$, with the highly probable category in causing ADRs were bisoprolol and ramipril. ADRs that mostly occurred were in the mild category. ADRs monitoring in CHF patients is especially important to achieve optimal therapeutic results.
\end{abstract}

Keywords: pharmacovigilance; adverse drug reactions; congestive heart failure

*corresponding author

Email: ditamarina.l@gmail.com

\section{INTRODUCTION}

Adverse drug reactions (ADRs) are adverse or undesired responses to a drug and occur at doses typically used in humans for prevention, diagnosis, treatment of disease, or for modification of physiological functions (BPOM RI, 2011; Wadhwa et al., 2018). ADRs are one of the major problems in the health care system (Wadhwa et al., 2018). ADRs need attention because they can lead to decreased quality of life, increased visits to doctors, hospital admissions, and even death (Christianie et al., 2008). In another survey, $85 \%$ of respondents stated that they were associated with at least one drugrelated problem, such as drug interaction, experiencing a dangerous side effect, or receiving the wrong drug (Alomar, 2014).

Heart failure is a progressive health problem with high mortality and morbidity rates in both developed and developing countries including Indonesia, even in Indonesia the age of heart failure patients is relatively younger than in Europe and America accompanied by a more severe clinical appearance (PERKI, 2015). Heart failure is a common, costly, and potentially debilitating syndrome associated with very complex drug regimens and many comorbidities. All of these factors can increase the risk of exacerbation of heart failure through direct myocardial toxicity, drug-drug interactions, or both (Wankhede, Pardeshi, Ghorpade, \& Ghongane, 2018).

Currently, interventions to prevent and treat cardiovascular disease are available, such as pharmacological treatments for the treatment of elevated LDL cholesterol levels (statins), increased blood pressure (thiazides, $\beta$-blockers, calcium channel blockers, angiotensin converting enzyme inhibitors or angiotensin receptor blockers) and platelet function inhibitors (antiplatelet agents such as low-dose aspirin) (Wankhede et al., 2018). The drugs used for the management of cardiovascular disease are not necessarily without side effects. They can have adverse consequences if not properly monitored. The increasing number of drugs in cardiac patients creates a tendency to cause drugrelated problems such as ADRs, drug-drug interactions, etc. Cardiovascular drugs reportedly accounted for 9\% of treatment-related visits to health care providers. One in every five heart patients is known to have ADRs and $17.9 \%$ of these are preventable, which then requires intensive monitoring and reporting (Wadhwa et al., 2018). 
Given the consideration of cardiovascular disease as a major problem, whereas cardiovascular drugs can cause multiple ADRs, studies for ADRs detection and reporting are of utmost importance. Besides, warnings on the use of cardiovascular drugs and their limitations in pre-marketing trials for drug evaluation still exist in the literature in Indonesia related to pharmacovigilance. It is necessary to evaluate post-marketing ADRs induced by these drugs. This study aims to calculate the incidence of ADRs as well as their severity and to see the effect of various risk factors (sex, age, and comorbid disease) on the incidence of ADRs in CHF patients by retrospective data collection.

\section{METHODS}

The population in this study were CHF patients aged more than 20 years who were hospitalized at the NTB (Nusa Tenggara Barat/West Nusa Tenggara) Provincial Hospital in the period 2017 to 2019, which was a total of 1392 patients. The selection of age is because the number of inpatient cases of CHF patients has increased in prevalence from the age above 15 years based on data from the Ministry of Health 2017 and over 20 years based on data in the management information system of the NTB Provincial Hospital. This study is a retrospective study, so the research data were obtained from the medical records of inpatients at the NTB Provincial Hospital. The samples of the study were inpatients with a primary diagnosis was CHF and consumed CHF medications for at least a four weeks period who have received at least one cardiovascular drug, which was 325 patients.

ADRs definition referred to in this study are according to the Food and Drug Administration of the Republic of Indonesia (BPOM, Badan Pengawas Obat dan Makanan). ADRs defined as adverse or undesired responses to a drug and occur at doses typically used in humans for prevention, diagnosis, treatment of disease, or for modification of physiological functions (BPOM, 2019). ADRs can be classified into six types from type A reactions until type F reactions (WHO, MSH, \& USAID, 2007). In this study, type A reactions was chosen because it is common type of ADRs and is related to the drug dose given and the drug's pharmacological action, and are associated with high morbidity and low mortality. Side effects are an example of type A reactions. The assessment of the incidence of side effects was obtained from the symptoms complained by patients and from the assessment made by medical doctor who was reported and recorded in the medical record.

The assessment of the causality of ADRs was carried out using the Naranjo algorithm rating scale. This scale is a practical tool for assessing the probability that a particular reaction in a patient can be attributed to a particular drug. Meanwhile, the scale used for the assessment of severity is the Hartwig \& Siegel severity scale. The results of the assessment using this scale are divided into three categories, including mild, moderate, and severe, depending on the severity of the suspected reaction.

The instrument in this study was a patient data collection sheet containing the patient's identity, history of patient drug use, patient's subjective and objective data were related to the incidence of ADRs as well as patient's symptoms and supportive laboratory data; then, ADRs evaluation sheet with Naranjo Algorithm and ADRs severity assessment sheet using Hartwig \& Siegel scale. Data collection was carried out by tracing the patient's medical records to select patients who met the inclusion criteria (patient with $\mathrm{CHF}$ as main diagnosa and patients receiving cardiovascular drugs at least four weeks) and the data listed in the medical records became the basis for filling out patient data tracking sheets and ADRs evaluation sheets and ADRs severity levels. Data collection was carried out by the researchers themselves.

Collected data were summated and were entered into the Microsoft-excel sheet and was analyzed using SPSS (Statistical Package for Social Science). Data analysis was performed using univariate analysis that categorical data were presented in the form of frequency and percentage. While bivariate analysis is using the Chi-square test that was performed to find out the effect of various risk factors and incidence of ADRs. P-value from the result of Chi-square test $<0.05$ is considered as statistically significant. The result of the study was presented in the form of text, tables, and figures.

\section{RESULTS AND DISCUSSION}

\section{Respondent Characteristics}

Characteristics of respondents in this study were grouped by sex, age, number of comorbid diseases, and stage of CHF. Data on the characteristics of CHF patients as study respondents can be seen in Table 1 . In the study, there were more male patients than female, $58 \%$ and $42 \%$ respectively. Several other studies also showed similar results (Mehta \& Cowie, 2006; Razzolini \& Lin, 2015). Likewise, the data on the non-communicable disease profile in 2016 shows that the number of cases with a diagnosis of heart failure who are hospitalized in hospitals in Indonesia (SIRS 2015) is more in men than women (Kemenkes.RI, 2016). Men have a higher incidence of heart failure, but women survive longer after heart failure and women tend to be older with a diagnosis of heart failure (Razzolini \& Lin, 2015; Regitz-Zagrosek et al., 2016; Strömberg \& Mårtensson, 2003). 
Table 1. Number of CHF patients characteristics as respondents

\begin{tabular}{|c|c|c|}
\hline \multirow{2}{*}{ Characteristics } & \multicolumn{2}{|c|}{ Total } \\
\hline & Qty* & $(\%)$ \\
\hline Number of Patient & \multicolumn{2}{|c|}{$\mathrm{N}=325$} \\
\hline \multicolumn{3}{|l|}{ Sex } \\
\hline Men & 190 & $58.5 \%$ \\
\hline Women & 135 & $41.5 \%$ \\
\hline \multicolumn{3}{|l|}{ Age } \\
\hline $20-60$ & 181 & $55.7 \%$ \\
\hline$>60$ & 144 & $44.3 \%$ \\
\hline \multicolumn{3}{|l|}{ Comorbidity } \\
\hline 0 & 37 & $11.4 \%$ \\
\hline 1 & 127 & $39.1 \%$ \\
\hline 2 & 95 & $29.2 \%$ \\
\hline 3 & 55 & $16.6 \%$ \\
\hline 4 & 9 & $2.8 \%$ \\
\hline 5 & 1 & $0.3 \%$ \\
\hline 6 & 2 & $0.6 \%$ \\
\hline \multicolumn{3}{|l|}{ Stage } \\
\hline $\mathrm{N} / \mathrm{A} * *$ & 220 & $67.7 \%$ \\
\hline 1 & 10 & $3.1 \%$ \\
\hline 2 & 35 & $10.8 \%$ \\
\hline 3 & 34 & $10.5 \%$ \\
\hline 4 & 26 & $8.0 \%$ \\
\hline
\end{tabular}

The basic genetics of sex differences in the XY chromosome configuration for males and XX for females. Several genes on the $\mathrm{Y}$ chromosome are associated with multiple cardiovascular risk factors, including increased blood pressure, increased low-density lipoprotein cholesterol, and a tendency to myocardial infarction (Razzolini \& Lin, 2015). Estrogens reduce catecholamine-induced vasoconstriction, increase vasodilation, and may increase $\beta 2$-adrenergic receptor response. A decrease in estrogen levels can increase the sensitivity of the heart to catecholamine (RegitzZagrosek et al., 2016).

The data from the study showed that patients who experienced ADRs was $56 \%$ of the patients in the adult category (20-60 years), were more than the elderly patients $(44 \%)$. Similar things were also recorded in the data profile on non-communicable diseases in 2016 by the Ministry of Health, where most cases of heart failure occurred in the 45-64 year age group (Kemenkes.RI, 2016).
It can be seen that the comorbidity of patients with the highest prevalence were patients who had two comorbidities (39\%) (Table 1). Various comorbidities that occur in patients include disorders of the circulatory system (coronary artery disease, ischemic cardiomyopathy, dilated cardiomyopathy), the respiratory system (pneumonia, pleural effusion), as well as endocrine and metabolic disorders (diabetes, diabetic nephropathy). The presence of information about comorbidities (comorbidities) in CHF patients is important because comorbidities can affect the treatment of CHF itself, even therapy for comorbid diseases can worsen symptoms and conditions of heart failure (e.g. use of non-steroids anti inflammation drug), and drugs used for CHF and comorbidities may interact (PERKI, 2015).

Staging in CHF patients is performed to assess the severity of the patient's CHF disease according to the criteria published by the NYHA (New York Heart Association). This is based on symptoms related to functional capacity which include the patient's limited physical activity, ability to breathe normally, and/or chest pain. The results of the CHF classification in this study (Table 1) show that most of the patient data (68\%) were not equipped with patient staging information. Perhaps this is because not all cardiologists who treat $\mathrm{CHF}$ patients are accustomed to including patient stages on medical records. However, this made us unable to analyze the effect of a stage in CHF patients on the incidence of ADRs.

\section{Drugs in the Management of CHF}

The use of drugs in the treatment of CHF is mostly polypharmacy. Furosemide is most widely prescribed in the treatment of CHF $(n=286,23 \%)$ followed by spironolactone $(n=231,19 \%)$ (Table 2$)$. The combination of the diuretic class furosemide and spironolactone can reduce the risk of hypokalemia and hypomagnesemia, and concomitant use with ACEI (Angiotensin Converting Enzyme Inhibitor) may reduce comorbid in heart failure (PERKI, 2015). The results of the same study were reported (Rich, 2011). In a retrospective study, the results showed that the spironolactone drug is usually combined with the ACEI and ARB drug classes. The combination of ACEI and ARB was frequently prescribed for patients without established indications and was associated with an increased risk of adverse renal outcomes. This combination can improve ventricular function, improve patient survival, and reduce the number of hospitalizations (Anand \& Tamura, 2012; McAlister et al., 2011).

The next most widely used drug by CHF patients in this study was bisoprolol $(\mathrm{n}=198(16 \%)$. The efficacy of using $\beta$-blocker drugs was studied in a prospective randomized control trial with a hazard ratio of 0.86 (0.74-0.99) (Palau et al., 2020). Patients who received 
Table 2. Frequency of the usage of CHF medications at the NTB Provincial Hospital

\begin{tabular}{lll}
\hline Drugs & Qty* & $(\mathbf{N}=\mathbf{1 2 2 4})^{* *}$ \\
\hline Furosemide & 286 & $23 \%$ \\
Spironolactone & 231 & $19 \%$ \\
Bisoprolol & 198 & $16 \%$ \\
Lisinopril & 42 & $3 \%$ \\
Isosorbide Dinitrate (ISDN) & 67 & $5 \%$ \\
Candesartan & 77 & $6 \%$ \\
Ramipril & 119 & $10 \%$ \\
Valsartan & 26 & $2 \%$ \\
Amlodipin & 32 & $3 \%$ \\
Digoxin & 117 & $10 \%$ \\
Hydrochlorothiazide (HCT) & 2 & $0.2 \%$ \\
Captopril & 5 & $0.4 \%$ \\
Carvedilol & 7 & $1 \%$ \\
Nitroglycerin & 15 & $1 \%$ \\
\hline
\end{tabular}

* Qty: quantity

** N: amount of total drugs

digoxin and ISDN therapy were $117(10 \%)$ and $67(5 \%)$ respectively. Giving a combination of digoxin and ISDN can slow the ventricular rate, symptomatic relief, and decrease hospital admission rates, administration of this drug is titrated from the minimum dose then titrated up to the target dose accompanied by drug monitoring effect (PERKI, 2015). ISDN is commonly prescribed to enhance activity tolerance in patients with $\mathrm{CHF}$, in which nitrate induced vasodilatation starts at a cellular level by the activation of the enzyme. In patients with congestive heart failure, vasodilation induces a substantial reduction in biventricular filling pressure. Moreover, it reduces systemic and pulmonary vascular resistance and systemic arterial blood pressure (Redfield et al., 2015).

Nitroglycerin was administered to 15 patients (2\%) and its derivatives were used in the treatment of CHF because of the beneficial effects of nitroglycerin, which can reduce preload and heart muscle overload, reduce pulmonary artery pressure, and reduce vascular and peripheral resistance (Rich, 2011).

\footnotetext{
ADRs Incidence Rate (ADRs Causality and Severity Assessment)

In CHF patients $(\mathrm{n}=325)$, the incidence of ADRs occurred in 223 patients $(69 \%)$, which was higher than patients without ADRs (31\%) (Figure 1). The higher incidence rate in patients with ADRs compared to those without ADRs is similar to previous study, where ADRs were recorded in $67 \%$ patients while patients without ADRs were 33\% patients (Catananti et al., 2009).
}

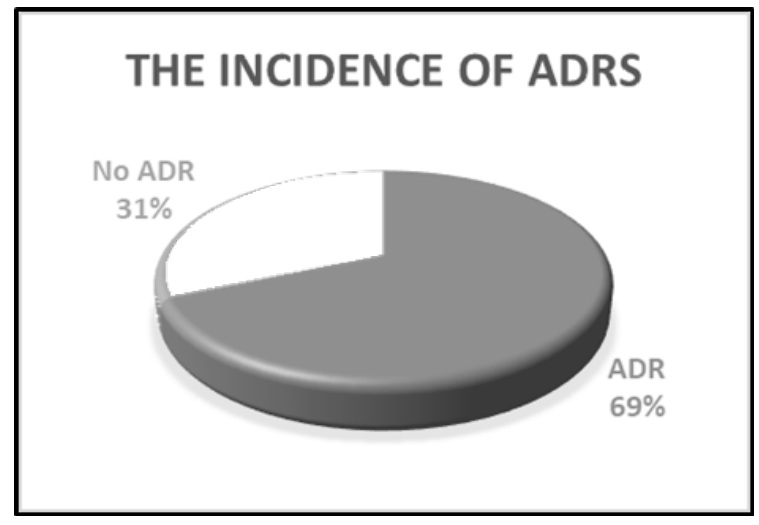

Figure 1. Diagram of the Incidence of ADRs in CHF Patients at the NTB Provincial Hospital

Causality analysis is an evaluation process carried out to determine or enforce a causal relationship between side effects that occur or are observed and drug use by patients (BPOM RI, 2012). Determining a clinical event is difficult, whether the event is ADRs or due to the patient's primary deterioration. If it is an ADRs, then it is necessary to know which drug caused it, as many patients take multiple medications when they are sick, especially if they are hospitalized.

The results of the ADRs causality assessment using the Naranjo Algorithm scale in 446 total cases of ADRs that occured (Table 3) showed the status of the ADRs incidence rate were $4(0.9 \%)$ highly probable, 187 (41.9\%) probable, and 255 (57.2\%) possible. The drugs that give rise to ADRs with a highly probable status were bisoprolol which causes bradycardia and ramipril which causes cough.

The results of research on monitoring and reporting adverse drug reactions due to cardiovascular drug also showed that the most common drug class implicated in ADRs was observed to be $\beta$-blockers especially bisoprolol $(14.68 \%)$ and the majority of patients experienced bradycardia $(10.09 \%)$ followed by hypotension (9; $8.26 \%$ ) (Wadhwa et al., 2018). Meanwhile, dry and persistent cough is a side effect of well-described ACEI drugs and the incidence of ACEI-related cough has been reported to be in the range of $5 \%$ to $35 \%$. (Dicpinigaitis, 2006). This study showed that ramiprilrelated cough occurred in $7.1 \%$ of Polish patients using ramipril therapy (Wyskida et al., 2012). ACEI-induced cough only occurs in susceptible individuals and is not dose-related. Therefore, this is an idiosyncratic reaction (Y1lmaz, 2019).

The ADRs severity assessment using the Hartwig and Siegel scale showed that the most ADRs categories were level $1(76.0 \%)$, followed by level $2(17.3 \%)$, level $3(6.5 \%)$, and level 4A (0, 2\%). Levels 1 and 2 
Table 3. Results of the naranjo algorithm causality assessment and the severity of ADRs with Hartwig \& Shiegel Scale in CHF Patients at the NTB Provincial Hospital

\begin{tabular}{lll}
\hline Naranjo Algorithm & Incidence of ADRs & $(\mathbf{N}=\mathbf{4 4 6})$ \\
\hline Highly Probable & 4 & $(0.9 \%)$ \\
Probable & 187 & $(41.9 \%)$ \\
Possible & 255 & $(57.2 \%)$ \\
\hline Hartwig \& Siegel's Scale & Incidence of ADRs & $(\mathbf{N}=\mathbf{4 4 6 *})$ \\
\hline Mild & & \\
Level 1 & 339 & $(76.0 \%)$ \\
Level 2 & 77 & $(17.3 \%)$ \\
Moderate & & \\
Level 3 & 29 & $(6.5 \%)$ \\
Level 4A & 1 & $(0.2 \%)$ \\
\hline
\end{tabular}

$* \mathrm{~N}$ : amount of total ADRs

are included in the mild category, while levels 3 and $4 \mathrm{~A}$ are in the moderate category. The mild severity category of ADRs are those that do not require a change in treatment with the suspected drug, these reactions are relatively manageable over time without much therapeutic intervention and do not contribute to the length of stay (LOS) in hospital. As for the moderate category, this reaction usually requires therapeutic intervention but this reaction can still be resolved before 24 hours by changing drug therapy or specific treatment so that the reaction does not occur in the future. In this category, the ADRs reaction can cause a length of stay of at least 1 day or the ADRs that arise can be a basis for consideration into treatment (Surjeet \& Wafai, 2012). The target of ADRs reporting and monitoring programs is to identify and quantify the risks associated with drug use and thus promote rational drug use. The pharmacist's involvement in patient care can assist in the prevention and early detection of ADRs (Ponnusankar, Tejaswini, \& Chaitanya, 2015).

\section{Type of ADRs in CHF Patients}

Types of ADR based on suspected complaints were ADR reactions reported by patients and reported to medical personnel from the start of the use of CHF drugs, and then classified according to the organ of influence. The total number of ADR reactions that occurred was 368 cases (Table 4). The types of ADR with the most errors were disorders of the nervous and joint systems as much as $136(37 \%)$, impaired kidney function by $116(32.1 \%)$, gastrointestinal disorders as much as $81(22.4 \%)$ and other complaints 40 (24\%).

The impaired renal function that occurred in this study was due to the use of diuretic drugs (ex: furosemide, spironolactone) including increased serum creatinine and electrolyte disturbances (potassium, sodium). The use of diuretic drugs can also cause hyperuricemia. The results showed that patients with kidney disorders had the highest increase in serum creatinine by 70 $(19 \%)$ cases and the least was hyperkalemia 4 (1.1\%). ACEI class drugs such as captopril and lisinopril can cause hyperkalemia because they work by inhibiting the change of angiotensin I to angiotensin II, causing a decrease in aldosterone production and will cause an increase in potassium concentration (Prasetyo \& Chrisandyani, 2010).

It has been reported in the study at a hospital in Iran where the percentage of ADRs was greater in gastrointestinal after administration of CHF drugs, this is due to drug therapy more than one that is can be a factor in gastrointestinal disorders (Mohebbi et al., 2010). In general, gastrointestinal disturbances are mild ADRs but can be severe and require adjustment of therapy.

Another complaint that was often encountered after administration of CHF drugs was dry cough which occurred in $19(5.2 \%)$ patients, the use of ACEI could block the degradation of bradykinin and stimulate the synthesis of substances that cause vasodilation, including prostaglandin E2 and prostacyclin, an increase in bradykinin increases the blood pressure-lowering effect of ACEI but is also responsible for the side effect of a dry cough that is frequently seen with ACEI use, the same was reported in the study where the percentage of ADRs incidence in the form of dry cough was the most common side effect (Wankhede et al., 2018).

Heart rhythm disturbances (bradycardia) and hypotension occurred in $11(3 \%)$ patients, ARB class drugs can cause a risk of renal impairment, bradycardia, hyperkalemia, 
Table 4. Frequency of Type ADRs in CHF Patients at the NTB Provincial Hospital

\begin{tabular}{lll}
\hline Kind of ADRs & $\begin{array}{l}\text { Qty } \\
(\mathbf{N}=\mathbf{3 6 8})\end{array}$ & $\mathbf{( \% )}$ \\
\hline Gastrointestinal system disorder & 81 & $(22.4 \%)$ \\
Muscles, joints, nervous system disorder & 136 & $(37.7 \%)$ \\
Skin reaction & 5 & $(1.4 \%)$ \\
Heart rhythm disturbances and hypotension & 11 & $(3.1 \%)$ \\
Impaired kidney function & 116 & $(32.1 \%)$ \\
Others & 19 & $(5.2 \%)$ \\
\hline Total & 362 & $(100 \%)$ \\
\hline
\end{tabular}

and hypotension, the same study results have been previously reported in a Systematic Review Literature, 3,834 patients in hospital care who experienced cardiovascular events after ARB administration but in the mild category (Bots et al., 2019).

Skin reactions in the form of rash and itching occurred in $5(1.4 \%)$, reported the most common incidence of cutaneous adverse drug reaction (CADR) is caused by bisoprolol which is a $\beta$-Blocker group (Wankhede et al., 2018). Management of skin reactions is generally given antihistamine class drugs as long as the condition is still complained of and if it is known the drug causing the skin reaction, treatment can be continued without the causative drug.

Relationship of risk factors and the incidence ADRs in CHF patients

All drugs can produce ADRs, but not all patients experience the same levels and types of ADRs. Many factors influence the occurrence of ADRs. Some of these factors can be changed such as smoking or alcohol intake, others that cannot be changed such as age, presence of other diseases, or genetic factors (Alomar, 2014). The results of the chi-square test analysis (Table 5) showed that the risk factors in patients had no significant effect on the incidence of ADRs in CHF patients, such as gender $(p=0.172)$, age $(p=0.846)$ and comorbidity $(p=0.326)$. This is because in each of these data it is seen that the highest value for the incidence of ADRs for each risk factor is only in one type of group (Table 5). For example, for gender risk factors, the incidence value of ADRs whether ADRs appeared or not, only occurred in the male group, as well as the risk factors for age and comorbidity. A systematic review examining sex differences in ADRs to the treatment of heart failure also showed that the study had no evidence of sex differences in the incidence of ADRs with ARBs and $\beta$-blockers (Bots et al., 2019).
Table 5. Risk Factors for ADRs in CHF Patients in NTB Provincial Hospital

\begin{tabular}{llll}
\hline \multirow{2}{*}{ Risk Factor } & \multicolumn{2}{c}{ Incidence of ADRs } & \\
\cline { 2 - 3 } & Yes & No & \\
Sex & & & \\
$\quad$ Men & 136 & 54 & 0.172 \\
Women & 87 & 48 & \\
\hline Age & & & \\
$20-60$ & 123 & 53 & 0.846 \\
$>60$ & 100 & 49 & \\
\hline Comorbidities & & & 0.326 \\
$\quad$ With & 195 & 93 & \\
Without & 28 & 9 & \\
\hline
\end{tabular}

Risk factors such as gender, age, and presence or absence of comorbid diseases did not show a significant association with the incidence of ADRs. Therefore, to prove the significance of this relationship and to produce more complex data, it is necessary to carry out further research with a larger number of samples and different research methods.

\section{CONCLUSION}

The prevalence of ADRs in CHF patients in this study was $69 \%$. However, the most prevalent severity of ADRs in CHF patients was mild ADRs. The drugs that were included in the highly probable category in causing ADRs in CHF patients were bisoprolol and ramipril, while the drugs that caused the highest level of severity (level 4A) were bisoprolol. Therefore, ADRs monitoring in $\mathrm{CHF}$ patients is especially important to achieve optimal therapeutic results and prevent the potential for the development of more severe ADRs. 


\section{ACKNOWLEDGMENT}

This research was supported and funded by the beginner lecturer research program held by the Ministry of Research, Technology and Higher Education of the Republic of Indonesia and in collaboration with the NTB Provincial Hospital as a research site.

\section{CONFLICT OF INTEREST}

This research has no conflict of interest.

\section{REFERENCES}

Alomar, M. J. (2014). Factors affecting the development of adverse drug reactions ( Review article ). Saudi Pharmaceutical Journal, 22(2), 83-94. https://doi. org/10.1016/j.jsps.2013.02.003

Anand, S., \& Tamura, M. K. (2012). Combining Angiotensin Receptor Blockers With ACE Inhibitors in Elderly Patients. American Journal of Kidney Disease, 59(1), 11-14. https://doi.org/10.1053/j. ajkd.2011.09.002.Combining

Bots, S. H., Groepenhoff, F., Eikendal, A. L. M., Tannenbaum, C., Rochon, P. A., Regitz-Zagrosek, V., Miller, V. M., Day, D., Asselbergs, F. W., den Ruijter, H. M. (2019). Adverse Drug Reactions to GuidelineRecommended Heart Failure Drugs in Women: A Systematic Review of the Literature. JACC: Heart Failure, 7(3), 258-266. https://doi.org/10.1016/j. jchf.2019.01.009

BPOM, RI. (2019). Panduan deteksi dan pelaporan efek samping obat untuk tenaga kesehatan. 1-26.

BPOM RI. Peraturan Badan pengawas Obat dan Makanan Republik Indonesia No HK.03.1.23.12.11.10690 Tahun 2011 Tentang Penerapan Farmakovigilans Bagi Industri Farmasi. , Badan Pengawas Obat dan Makanan RI (2011).

BPOM RI. (2012). Pedoman Monioring Efek Samping Obat (MESO) Bagi Tenaga Kesehatan. Direktorat Pengawasan Distribusi Produk Terapetik dan PKRT Badan Pom RI, 1-35.

Catananti, C., Liperoti, R., Settanni, S., Lattanzio, F., Bernabei, R., Fialova, D., Landi, F., Onder, G. (2009). Heart failure and adverse drug reactions among hospitalized older adults. Clinical Pharmacology and Therapeutics, 86(3), 307-310. https://doi.org/10.1038/ clpt.2009.89
Christianie, M., Setiati, S., Trisna, Y., \& Andrajati, R. (2008). Kejadian Reaksi Obat yang Tidak Dikehendaki yang Menyebabkan Pasien Usia Lanjut Dirawat di Ruang Perawatan Penyakit Dalam Instalasi Rawat Inap B Rumah Sakit Dr. Cipto Mangunkusumo. Majalah Ilmu Kefarmasian, 5(3), 138-149. https://doi.org/10.7454/ psr.v5i3.3428

Dicpinigaitis, P. V. (2006). Angiotensin-Converting Enzyme Inhibitor-Induced Cough, ACCP Evidencebased Clinical Practice Guidelines. Chest Journal, 129(1), 169S-173S. https://doi.org/10.1378/chest.129.1

Kemenkes.RI. (2016). Profil Penyakit Tidak Menular Tahun 2016. Jakarta.

McAlister, F. A., Zhang, J., Tonelli, M., Klarenbach, S., Manns, B. J., \& Hemmelgarn, B. R. (2011). The safety of combining angiotensin-converting-enzyme inhibitors with angiotensin-receptor blockers in elderly patients: A population-based longitudinal analysis. Canadian Medical Association Journal, 183(6), 655-662. https:// doi.org/10.1503/cmaj.101333

Mehta, P. A., \& Cowie, M. R. (2006). Gender and heart failure: A population perspective. Heart, 92(SUPPL. 3), 14-18. https://doi.org/10.1136/hrt.2005.070342

Palau, P., Seller, J., Domínguez, E., Gómez, I., Ramón, J. M., Sastre, C., Espriella. R., Santas, E., Miñana, G., Chorro, F. J., González-Juanatey, J. R., Núñez, J. (2020). Beta-blockers withdrawal in patients with heart failure with preserved ejection fraction and chronotropic incompetence: Effect on functional capacity rationale and study design of a prospective, randomized, controlled trial (The Preserve-HR trial). Clinical Cardiology, 43(5), 423-429. https://doi.org/10.1002/clc. 23345

PERKI. (2015). Pedoman Tatalaksana Gagal Jantung. In Pedoman Tatalaksana Gagal Jantung (Pertama). Perhimpunan Dokter Spesialis Kardiovaskular Indonesia.

Ponnusankar, S., Tejaswini, M., \& Chaitanya, M. (2015). Assessment of adverse drug reactions based on spontaneous signals at secondary care public hospital. Indian Journal of Pharmaceutical Sciences, 77(4), 490493. https://doi.org/10.4103/0250-474X.164771

Prasetyo, S. D., \& Chrisandyani, D. (2010). Gambaran Efek Samping ObatAntihipertensi Pada Pasien Hipertensi di Instalasi Rawat Inap RS PKU Muhammadiyah Yogyakarta Periode Oktober-November 2009. Majalah Farmaseutik, 6(2), 19-25. 
Razzolini, R., \& Lin, C. D. (2015). Gender diff erences in heart failure. Italian Journal of Gender-Specific Medicine, (June), 15-20.

Redfield, M. M., Anstrom, K. J., Levine, J. A., Koepp, G. A., Borlaug, B. A., Chen, H. H., LeWinter, M. M., Joseph, S. M., Shah, S. J., Semigran, M. J., Felker, G. M., Cole, R. T., Reeves, G. R., Tedford, R. J., Tang, W. H. W., McNulty, S. E., Velazquez, E. J., Shah, M. R., Braunwald, E. (2015). Isosorbide Mononitrate in Heart Failure with Preserved Ejection Fraction. New England Journal of Medicine, 373(24), 2314-2324. https://doi. org/10.1056/nejmoa1510774

Regitz-Zagrosek, V., Oertelt-Prigione, S., Prescott, E., Franconi, F., Gerdts, E., Foryst-Ludwig, A., Mass, A.H.EM., Kautzky-Willer, A., Knappe-Wegner, D., Kintscher, U., Heinz Ladwig, K., Schenck-Gustafsson, K., Stangl, V. (2016). Gender in cardiovascular diseases: Impact on clinical manifestations, management, and outcomes. European Heart Journal, 37(1), 24-34. https://doi.org/10.1093/eurheartj/ehv598

Rich, M. W. (2011). Pharmacotherapy of heart failure in the elderly: Adverse events. Heart Failure Reviews, 17(4-5), 589-595. https://doi.org/10.1007/s10741-0119263-1

Strömberg, A., \& Mårtensson, J. (2003). Gender differences in patients with heart failure. European Journal of Cardiovascular Nursing: Journal of the Working Group on Cardiovascular Nursing of the European Society of Cardiology, 2(1), 7-18. Retrieved from https://doi.org/10.1016/S1474-5151(03)00002-1

Surjeet, S., \& Wafai, Z. (2012). Adverse Drug Reaction Monitoring at Tertiary Care Hospital S.K.I.M.S. JKPractitioner, 17(1-3), 58-63.
Wadhwa, T., El Sheikh, S. G., \& Rao, P. G. M. (2018). Monitoring and Reporting of Adverse Drug Reactions Due to Cardiovascular Drugs in Patients Admitted to a Secondary Care Hospital in Northern Emiratea Prospective Surveillance Study. Indian Journal of Pharmacy Practice, 11(2), 71-78. https://doi. org/10.5530/ijopp.11.2.16

Wankhede, S. Y., Pardeshi, M. L., Ghorpade, V. V, \& Ghongane, B. B. (2018). An assessment of pattern of adverse drug reactions of cardiovascular drugs in a tertiary care institute. IJBCP: International Journal of Basic \& Clinical Pharmacology, 7(2), 273-277.

WHO, MSH, \& USAID. (2007). Drug and Therapeutics Committee Training Course: Assessing and Managing Medicine Safety. Drug and Therapeutics, 1-24. Retrieved from http://www.who.int/medicines/technical_briefing/ tbs/04-PG_Dug-Safety_final-08.pdf?ua=1

Wyskida, K., Jura-Szołtys, E., Smertka, M., Owczarek, A., \& Chudek, J. (2012). Factors that favor the occurrence of cough in patients treated with ramipril A pharmacoepidemiological study. Medical Science Monitor, 18(9), 21-28. https://doi.org/10.12659/ MSM.883336

Y1lmaz, İ. (2019). Angiotensin-converting enzyme inhibitors induce cough. Turkish Thoracic Journal, 20(1), 36-42. https://doi.org/10.5152/TurkThoracJ.2018.18014 